Ma'an M.Nayif BDS, MSc, PhD.

Manal A.Sultan BDS, MSc (Lect.)

Amer A.Sultan BDS, MSc (Lect.)

\section{Changing in Working Length and Canal Dimension Following Instrumentation with Hand and Rotary Instrument}

$\mathbf{X X}$

College of Dentistry, University of Mosul

$\mathbf{X X}$

College of Dentistry, University of Mosul

$\mathbf{X X}$

College of Dentistry, University of Mosul

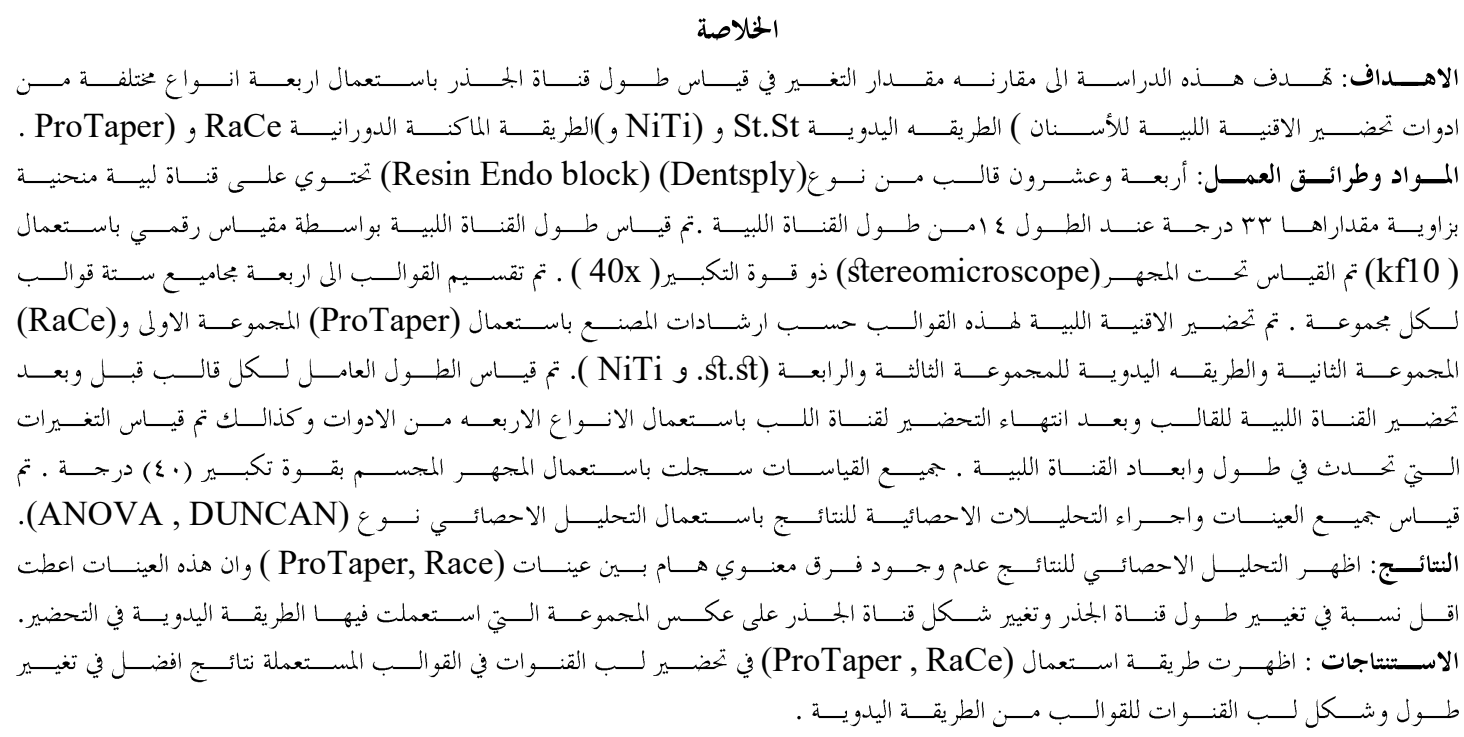

ABSTRACT

Aims: This study evaluated changes in working length (WL) and root canal dimension after instrumentation with hand instruments (St.St, NiTi) and rotary systems (RaCe, ProTaper). Materials and Methods: Twenty four resin blocks with a curve canal of $33^{\circ}$ angle at $(14 \mathrm{~mm})$ were selected for this study. Working length was measured by a digital measurement using a number (10k) file under stereomicroscope at $40 \mathrm{X}$. The specific sequence of instrumentation was system according to manufacturer's recommendation. The working length of the canal was measured again between each file and at the end of instrumentation. Pre and post-instrumentation microscopic photographs were taken and measurements of the root canal dimension change were measured with an image analysis programme. The difference in working length was analyzed using ANOVA and Duncan's test at 5\% level of significance. Result: Statistical analysis showed that there was no significance difference in the changing of the working lengths and canal dimension between the two rotary systems (ProTaper,RaCe). While there was a significant difference in the changing of the canal length and dimension between the two rotary systems (ProTaper, RaCe) and the hand instruments (St.St, NiTi). The amount of variation in working length and canal dimension obtained with both types of rotary instruments, was significantly less than that produced by hand instruments. Conclusion: The variation in working length were clinically not very significant between the two rotary NiTi instruments (ProTaper, RaCe)while it was significant with the hand instrument (St.St and NiTi).

Key words: Channing in working length, rotary sytem, manual instrument.

Nayif MM, Sultan MA, Sultan AA, Changing in Working Length and Canal Dimension Following Instrumentation with Hand and Rotary Instrument. Al-Rafidain Dent J. 2015; 15(2): 431-437.

Received: $18 / 6 / 2013$

Sent to Referees: $24 / 6 / 2013$

Accepted for Publication: 9/9/2013

\section{Introduction}

Shaping ability and cleaning effectiveness of various endodontic instruments are necessary request for successful root canal therapy $^{(1)}$. Consequently determining proper working length is essential for optimum canal shaping and cleaning. Working length considers the distance between coronal reference point and point at which canal preparation and obturation must end. Inaccuracy in working length could lead to different problems like over or under filling, postoperative pain then failure of endodontic therapy ${ }^{(2)}$. The incidence of such compromization might be 
increases in crown down techniques due to the changes in working length between preliminary measure and after instrumentation ${ }^{(3)}$. Cases with curvature presents in canal could face more challenges in regard to variation of canal length. Although comparison between manual technique instrumentation and different rotary systems was studied with no difference in canal curvature but further study is needed ${ }^{(4)}$. Using simulated resin canals provide reproducibility and standardization in terms of degrees and curvatures ${ }^{(5)}$.

Stainless steel file was commonly used with long history that have been shown to create aberrations, probably as a result of the inherent stiffness ${ }^{(6)}$. Weine ${ }^{(7)}$ reported that most instrumentation techniques with stainless steel instruments in curved canals result in apical transportation. This makes obtaining a successful apical seal more difficult ${ }^{(7,8)}$. Nickel-titanium (NiTi) rotary systems were introduced to improve root canal preparation and fasten procedure. A variety of instrument systems have been developed and described for better outcome of root canal treatment. Instruments may different in their cross section, tip, cutting design and taper in addition to the alloy type. Protaper and $\mathrm{RaCe}$ systems are among the commonly used NiTi rotary systems. Hand NiTi instruments can also be selected instead of rotary instruments in teeth with difficult canal anatomy and/or problematic handpiece access ${ }^{(9)}$. The ProTaper for hand use (HPT) appeared as an alternative NiTi instrument to the rotary ProTaper, embodying the same philosophy, indications, and sequence, but at a lower cost.

The aim of this study was to evaluate pre and post instrumentation variations in canal working length and dimension in simulated curved resin block canals prepared with hand and rotary NiTi systems.

\section{Materials and Methods}

Twenty four resin endodontic blocks were used with the following dimension $(10 \times 19 \mathrm{~mm})$. Coronal part have $0.02 \mathrm{~mm}$ taper while the curvature at 14 th $\mathrm{mm}$ with a $33^{\circ}$ angle (Dentsply-Maillefer, USA) (Figure $(1, \mathrm{~A}))$. Blocks were divided into four groups according to the instrument systems $(\mathrm{n}=6)$ :

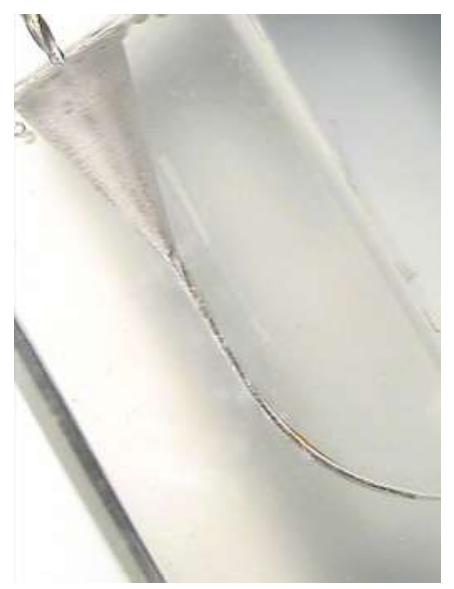

A

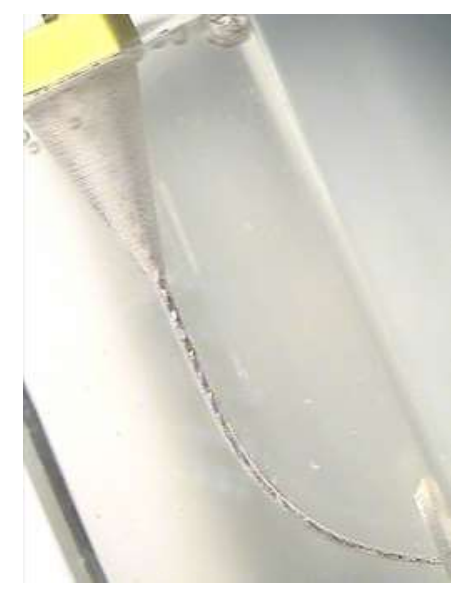

B

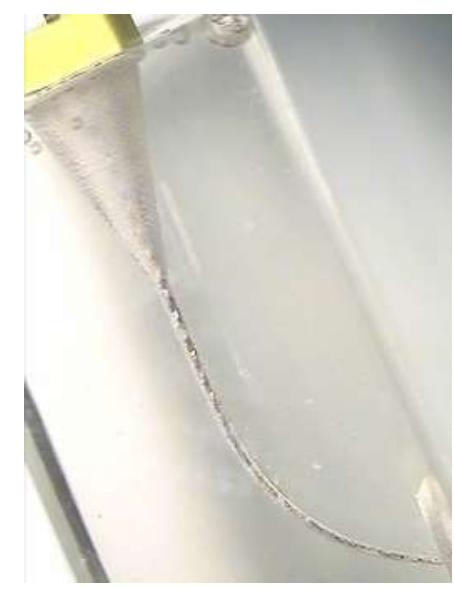

$\mathrm{C}$

Figure (1): Determination of working length .(A) K.file for determination of working length (B) ST.ST. hand instrument .(C) NiTi hand instrument.

Group I : Blocks were prepared with hand endodontic stainless steel $\mathrm{K}$ files (Manii, japan). Preparation method utilized for this group was crown down pressure-less technique. Instrument sizes used were (35\# to $15 \#)$ respectively as shown in (Figure $(1, \mathrm{~B}))$. The guide for manual instrumentation was to reach size before changing from size to size.

Group II: Similar to group I except using Nickel Titanium K files (Manii, japan) (Figure $(1, \mathrm{C})$ ).
Group III: Blocks were prepared with ProTaper rotary system (Dentsply-Maillefer, USA). This system is characterized by different taper within the same file. The manufacturer sequence was followed: $\mathrm{S} 1$ at $10 \mathrm{~mm}, \mathrm{SX}$ at $12 \mathrm{~mm}, \mathrm{~S} 1$ at $14 \mathrm{~mm}, \mathrm{~S} 2$ at 16 $\mathrm{mm}, \mathrm{F} 1$ at $18 \mathrm{~mm}, \mathrm{~F} 2$ at $18 \mathrm{~mm}, \mathrm{~F} 3$ at $18 \mathrm{~mm}$ (Figure (2,A)). The speed used was $300 \mathrm{rpm}$ and the gear used was $1: 16$ at $1.4 \mathrm{Ncm}$ torque. The instrumentation was continued until each file reaches the predesigned working length. 
Group IV : Blocks were prepared with $\mathrm{RaCe}(\mathrm{FKG})$ rotary system (DentsplyMaillefer, USA). This has twisted areas with straight non cutting areas and triangular section except for those with 0.02 taper which has a square section. The sequence followed

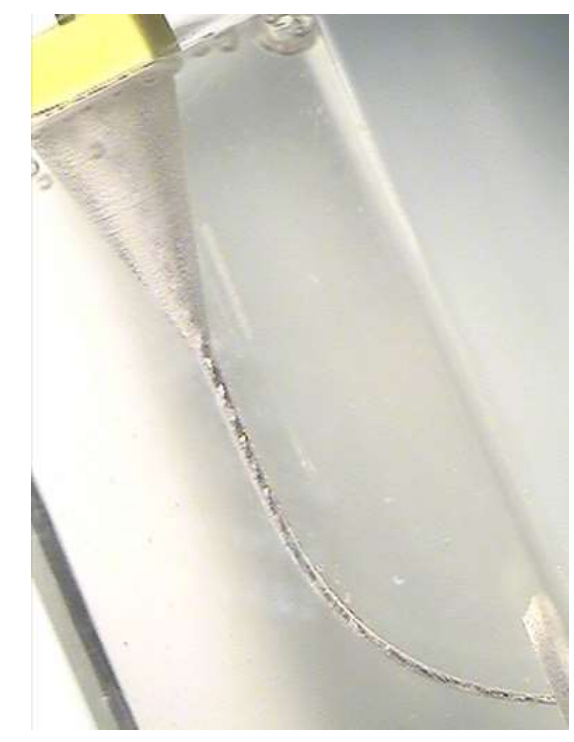

Figure (2): Pro Taper rotary instrument(A) .RaCe rotary instrument (B)

Contra-angle-hand piece (NSK EndoMate DT, NAKANISHI, INC, JAPAN) was used for the preparation with the rotary instruments, a torque of $1.4 \mathrm{Ncm}$ and speed of 300 rpm was used for all techniques.

For all groups, $5 \mathrm{ml}$ of irrigation solution with $(2.5 \%)$ sodium hypochlorite was used between each file in all techniques. An ethylene diamine tretraacetic acid gel was used between each file as a glyde lubricant (Glyde file Prep Dentsply). Pre and post instrumentation photographs were taken at $40 \mathrm{x}$ with Stereomicroscope (Motic, Italy).

An image analysis system Image $\mathbf{J}$ (Java), was used for the determination and measurements of the variations in the pre and post instrumentation working lengths and canal dimension. Image analysis program was used to measure the space difference between the elastic stopper of each file (that was :010-40 at $10 \mathrm{~mm}, 08-35$ at $12 \mathrm{~mm}, 06-25$ at $14 \mathrm{~mm}, 04-25$ at at $16 \mathrm{~mm}$, and $02-25$ at $18 \mathrm{~mm}$ also the instrumentation was continued until each file reaches the predesigned working length as shown in(Figure $(2, \mathrm{~B})$ ).

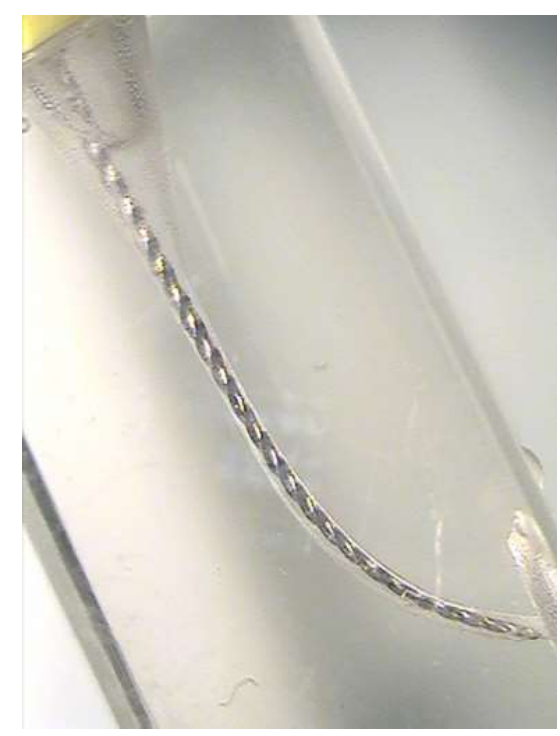

was pre adjusted at the initial working length) and the coronal surface of the endodontic block as with successive file instrumentations , the working length tends to be shortened. Only one view of the canal (lateral) was analyzed in this study, as this view shows the canal curvature while the frontal view was less significant.

For the purpose of evaluating the effect of different instrumentation systems on the dimension of the prepared canal, each of the prepared canals in the endodontic blocks were painted with methelyne blue dye (post instrumentation) and compared with a non instrumented painted canal (Figure (3)). The comparison was carried out by the use of steriomicroscope (Motic, Italy) at $40 \mathrm{X}$ magnification, the data were then analyzed using image analysis system Image J(Java) soft ware version $1.44 \mathrm{p}$. 


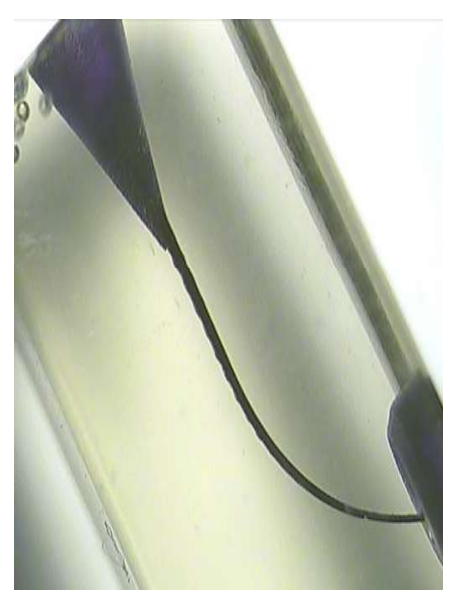

A

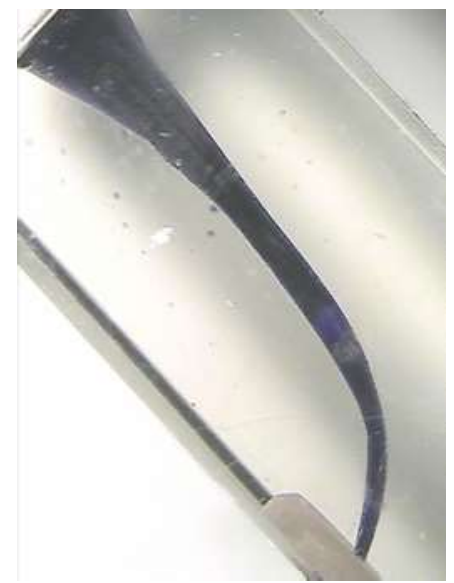

$\mathrm{C}$

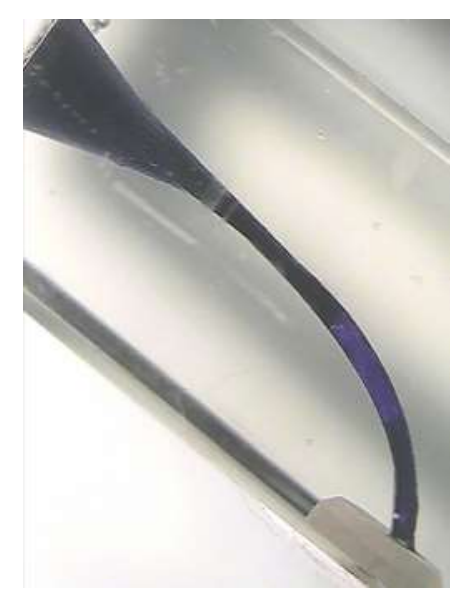

$\mathrm{B}$

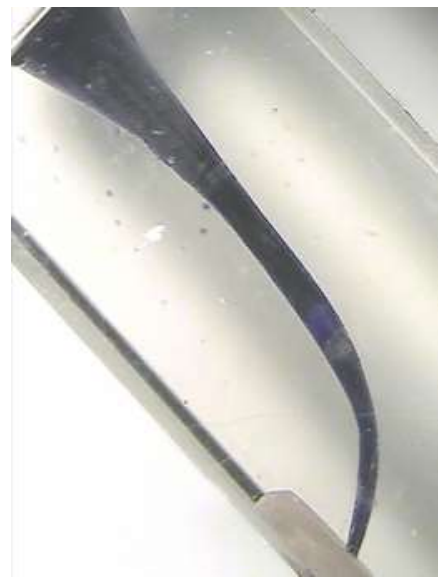

$\mathrm{D}$

Figure (3): Changing in canal dimension (A) non instrumented canal (B) instrumented canal

(St.St hand instrument), (C)rotary instrument (ProTaper) (D) rotary instrument (RaCe).

\section{Statistical analysis:}

A descriptive analysis was used to record means and standard deviations of

the differences in working lengths of each instrument system Table (1).

Table (1) : means and standard deviations of the differences in working lengths of each instrument system

\begin{tabular}{ccccccc}
\hline & & Size $\square$ 1 & size2 & size3 & size4 & size5 \\
\hline \multirow{2}{*}{ Pro T } & Mean & .01533 & .02833 & .16750 & .30500 & .40667 \\
& Std. Deviation & .004546 & .005164 & .082689 & .043243 & .025033 \\
\multirow{2}{*}{ RaCe } & Mean & .01250 & .03000 & .17333 & .29833 & .39500 \\
& Std. Deviation & .004183 & .007071 & .020656 & .036009 & .020736 \\
\multirow{2}{*}{ HI SS } & Mean & .03667 & .26667 & .32833 & .46667 & .58333 \\
& Std. Deviation & .012111 & .024221 & .051153 & .049261 & .024221 \\
\multirow{2}{*}{ HI NiTi } & Mean & .03333 & .24667 & .29833 & .43500 & .55000 \\
& Std. Deviation & .016330 & .030768 & .035449 & .036194 & .044721 \\
\multirow{2}{*}{ Total } & Mean & .02446 & .14292 & .24187 & .37625 & .48375 \\
& Std. Deviation & .014718 & .117916 & .088721 & .086266 & .090160 \\
\hline
\end{tabular}

*The size stand for the sequence of the instruments used in each different system used in this study. 
Changing in Working Length and Canal Dimension Following Instrumentation with Hand and Rotary Instrument

ANOVA was used to evaluate the effect of different instrumentation systems and instrumentation size, on the variation of

the pre and post instrumentation working lengths Table (2).

Table (2) : One way ANOVA evaluating the effect of different instrumentation systems and instrumentation size, on the variation of the pre and post instrumentation working lengths

\begin{tabular}{|c|c|c|c|c|c|c|}
\hline & & Sum of Squares & Df & Mean Square & $\mathbf{F}$ & Sig. \\
\hline \multirow{3}{*}{ Pro T } & Between Groups & .003 & 3 & .001 & 8.046 & .001 \\
\hline & Within Groups & .002 & 20 & .000 & & \\
\hline & Total & .005 & 23 & & & \\
\hline \multirow{3}{*}{ RaCe } & Between Groups & .312 & 3 & .104 & 258.175 & .000 \\
\hline & Within Groups & .008 & 20 & .000 & & \\
\hline & Total & .320 & 23 & & & \\
\hline \multirow{3}{*}{ HI SS } & Between Groups & .125 & 3 & .042 & 15.007 & .000 \\
\hline & Within Groups & .056 & 20 & .003 & & \\
\hline & Total & .181 & 23 & & & \\
\hline \multirow{3}{*}{ HI NiTi } & Between Groups & .137 & 3 & .046 & 26.392 & .000 \\
\hline & Within Groups & .035 & 20 & .002 & & \\
\hline & Total & .171 & 23 & & & \\
\hline \multirow{3}{*}{ Total } & Between Groups & .169 & 3 & .056 & 61.755 & .000 \\
\hline & Within Groups & .018 & 20 & .001 & & \\
\hline & Total & .187 & 23 & & & \\
\hline
\end{tabular}

*The size stand for the sequence of the instruments used in each different system used in this study.

Duncan test was used to evaluate the significant variation in pre and post treatment working lengths between the different systems Table (3). For the evaluation of the dimensional changes, ANOVA test was done, (Table (4)).

Table (3) : Duncan's Multiple Range Test evaluating the significance between the sum of working length variation in the four systems used.

\begin{tabular}{ccccc}
\hline System & No. & $\mathbf{1}$ & $\mathbf{2}$ & $\mathbf{3}$ \\
\hline Race & 6 & .8483 & & \\
ProTaper & 6 & .8700 & 1.3583 & \\
HI(Ni.Ti) & 6 & & & 1.5000 \\
HI(St.St) & 6 & & 1.000 & 1.000 \\
Sig. & & .137 & \\
\hline
\end{tabular}

Means for groups in homogeneous subsets are displayed.

a. Uses Harmonic Mean Sample Size $=6.000$.

Table (4) : Dimensional Changes With Different Systems

\begin{tabular}{cccccc}
\hline Systems & N & Mean & Standard D & \multicolumn{2}{c}{ Confidence interval } \\
\hline HI(St.St) & 6 & 9.1 & 0.775672 & 9.1983 & 9.8326 \\
HI(Ni.Ti) & 6 & 8.86 & 0.776316 & 8.1435 & 9.9653 \\
Pro Taper & 6 & 14.2 & 0.862796 & 13.5923 & 14.7254 \\
Race & 6 & 8.6 & 0.830462 & 7.4218 & 8.9863 \\
\hline
\end{tabular}

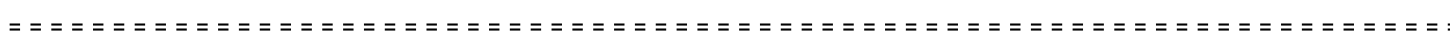




\section{Results}

ANOVA test Table (2) showed that there is a significant difference in the working length variations between the different instrument sizes of each systems (within group), in addition to a significant difference between the corresponding sizes from different instrumentation systems (between groups)

Statistical results showed that the greatest changes in between the pre and post instrumentation, working length were produced by stainless steel hand instruments, while the smallest changes were obtained by $\mathrm{RaCe}$ rotary instrumentation as shown in Table (3).

Duncan test showed that there was a significant difference in the value of the pre and post instrumentation working length, between the hand and rotary instruments, further more, the type of rotary instruments used did not affect the final result significantly, while there was a significant difference between canals length prepared with NiTi rotary system (Protap.Race) and those prepared with hand system (St.St \&NiTi)shown in Table (2) and Table (3).

The greatest change in canal dimension was obtained with Protaper system, while the smallest change was obtained with $\mathrm{RaCe}$ system Table (4).

\section{Discussion}

The present study shows that's no statistically significant in the decrease of canal length after instrumentation between the NiTi rotary instrument (Race,Protaper) compared to a statistical significant variations in canal length instrumented with hand instrument (St.St and Ni.Ti). These results are in agreement with the findings of other investigations on WL reduction after root canal shaping with stainless-steel hand files ${ }^{(10)}$, stainless-steel hand files plus Gates Glidden burs ${ }^{(11)}$, and NiTi rotary instruments $^{(10,11)}$. Schafer et al., ${ }^{(12)}$ compared the ProTaper and $\mathrm{RaCe}$ systems observing a greater loss of length with ProTaper at $35^{\circ}$ curvatures with a result of $0.38 \mathrm{~mm}$. For curvatures of $28^{\circ}$ a result of $0.26 \mathrm{~mm}$ was obtained; and withRaCe for a $28^{\circ}$ curvature the result was $0.16 \mathrm{~mm}$ and for $\mathrm{a} 35^{\circ}$ curvature, $0.20 \mathrm{~mm}$. These results do not coincide with the values obtained in this study because adifferent procedure was followed, using extracted teeth ${ }^{(13)}$. Yun et al., ${ }^{(14)}$ determined that ProTaper produces the greatest change in curvature and presents the greatest deformation as the dimeter increase coefficient is higher than that of other systems, in addition to the resistance offered by resin. The authors determined that the use of ProTaper must be controlled in narrow curved canals. Schafer et al., ${ }^{(12,13)}$ compared RaCe with ProTaper and established that $\mathrm{RaCe}$ maintained the original curvature perceptibly better than ProTaper, which coincides with the results obtained in this present study. Veltri et al.,(15) in a study on ProTaper saw that the preparations made by ProTaper focused on the canal, with minimum tendency to transport the curvatures; their results may be due to the high flexibility of the NiTi alloy.

Regarding the variations in canal dimension, ProTaper system showed the higher increase in values of canal dimension, the reasonable explanation for this is related to the instrument configuration and preparation method, ProTaper system is intended to produce a flare coronal part that involve the removal of considerably large amount of the prepared surface.

The use of simulated resin canals provides standardization in terms of degrees and curvature, in three dimensions. This model guarantees reproducibility and standardization of the experimental models but the results cannot be transferred to normal teeth due to the difference between resin and dentine. A force of (34-40) $\mathrm{kg} / \mathrm{mm}^{2}$ required to work dentine which is double the $(20-22) \mathrm{kg} / \mathrm{mm}^{2}$ required to work resin; furthermore, it is more difficult to remove the resin debris from the blocks $^{(16)}$.

\section{Conclusions}

After instrumentation of the resin blocks with the above mentioned rotary systems and hand system following the proposed methodology, the following conclusions were reached: both the rotary systems studied show a less amount of change in the working length , RaCe system show a better results regarding variation in canal dimension and in compare with the protaper and hand instruments. Hand instruments showed the highest amount in working length change.

\section{References}

1. Al-Fouzan KS: The microscopic diagnosis and treatment of a mandibular, second premolar with four canals. Int Endod J 2001, 34:406-410.

2. Plotino G, Grande NM, Pecci R, Bedini R, Pameijer CN, Somma F: Three dimensional imaging using micro computed tomography for studying tooth macro 
morphology. J Am Dent Assoc 2006, 137:1555-1561.

3. Rhodes JS, Pitt Ford TR, Lynch JA, Liepins PJ, Curtis RV: Micro-computed tomography: a new tool for experimental endodontology. Int Endod J 1999, 32:165-170.

4. Vertucci FJ: Root canal morphology and its relationship to endodontic procedures. Endod Topics 2005, 10:3-29.

5. de Alencar AH, Dummer PM, Oliveira HC, Pécora JD, Estrela C: Procedural errors during root canal preparation using rotary NiTi instruments detected by periapical radiography and cone beam computed tomography. Braz Dent J 2010, 21:543-549.

6. Friedman S: Prognosis of initial endodontic therapy. Endod Topics 2002, 2:59-88.

7. Weine FS: Initiating endodontic treatment. In Endodontic Therapy. 6 edition. Edited by: Weine FS. St. Louis, MO, USA: Mosby; 2004:106-110.

8. Yoshioka T, Villegas JC, Kobayashi C, Suda H: Radiographic evaluation of root canal multiplicity in mandibular first premolars. J Endod 2004, 30:73-74.

9. Hülsmann M, Peters OA, Dummer PMH: Mechanical preparation of root canals: shaping goals, techniques and means. Endod Topics 2005, 10:30-76.

10. Gekelman D, Ramamurthy R, Mirfarsi
S, Paqué F, Peters OA: Rotary nickeltitanium GT and ProTaper files for root canal shaping by novice operators: a radiographic and micro-computed tomography evaluation.

11. J Endod 2009, 35:1584-1588.

12. Schafer E, Vlassis M. Comparative investigation of two rotary nickle-titanium instruments : ProTaper versus RaCe.Part 1. Shaping ability in simulated curved canals. Int Endod J. 2004;37:229-38.

13. Schafer E,Vlassis M. Comparative investigation of two rotary nickel-titanium instruments: ProTaper versus RaCe. Part 2. Cleaning effectiveness and shaping ability in severely curved root canals of extracted teeth. Int Endod J. 2004;37:239-48.

14. Yun HH, Kim SK. A comparsion of the shaping abilities of 4 nickel-titanium rotary instruments in simulated root canals.Oral Surg Oral Med Oral Pathol Oral Radiol Endod. 2003;95:228-33.

15. Veltri M, Mollo A,Pini PP, Ghelli LF, Balleri P. In vitro comparison of shaping abilities of ProTaper and GT rotary files. J Endod. 2004;30:163-6.

16. Nagy CD, Bartha K, Bernath M, Verdes E, Szabo J. The effect of root canal morphology on canal shape following instrumentation using different techniques. Int Endod J. 1997;30:133-40. 